\title{
IMPLEMENTASI WEBSITE PENDIDIKAN BERBASIS ISO/IEC 9126-4 UNTUK MENINGKATKAN KUALITAS PENGGUNAAN
}

\author{
Lisa Devilia ${ }^{* 1}$ \\ Taqwan Thamrin ${ }^{\# 2}$ \\ Program Studi Sistem Informasi \\ Fakultas Ilmu Komputer \\ Universitas Bandar Lampung \\ Jl. Zainal Abidin Pagar Alam No. 26 \\ Labuhan Ratu Bandar Lampung 35142
}

\begin{abstract}
Abstrak
Website FIK UBL merupakan website pendidikan dari Fakultas Ilmu Komputer di Universitas Bandar Lampung.Nama domain dari website FIK UBL adalah www.fik.ubl.ac.id. Website FIK UBL merupakan subdomain dari website www.ubl.ac.id. Website tersebut mengunakan ac.id sebagai Country Code Top level domain, domain utamanya adalah UBL, dan Third level domainnya adalah FIK.ISO/IEC 9126-4 Metrik Kualitas Penggunaan digunakan untuk mengukur sejauh mana suatu produk memenuhi kebutuhan yang ditentukan pengguna untuk mencapai tujuan tertentu. Metriks adalah satuan untuk mengukur suatu perangkat lunak. Didalam ISO/IEC 9126-4 terdapat Metriks efektivitas, keamanan, produktivitas, dan kepuasan yang ditentukan dalam konteks metriks kualitas penggunaan. Penulisan Ilmiah ini secara spesifik akan terpusat pada implementasi website FIK UBL berbasis ISO/IEC 9126-4 Kualitas Penggunaan pada Metrik Efektivitas. Metrik Efektivitas mengukur ketepatan dan kelengkapan dengan tujuan yang dapat dicapai. Metrik Efektivitas merupakan salah satu dari empat metrik ISO/IEC 9126-4 Kualitas Penggunaan yang dipilih untuk dilakukan implementasi pada penelitian ini.
\end{abstract}

Keyword: Website, ISO/IEC 9126-4, Kualitas Penggunaan.

\section{PENDAHULUAN}

Teknologi semakin berkembang seiring dengan meningkatnya kebutuhan kita. Dalam memasuki dunia globalisasi, kita mengenal teknologi yang semakin maju untuk mempermudah melakukan berbagai kegiatan dalam kehidupan. Kemajuan di bidang transportasi, komunikasi, kesehatan, pendidikan, dan bidang lainnya merupakan contoh bahwa kita semakin memerlukan teknologi dalam kehidupan ini. Peranan teknologi dalam kehidupan manusia tidaklah diragukan lagi.Saat ini dunia telah mengenal suatu teknologi yang dinamakan internet. Dengan internet ini semua orang dapat berkomunikasi dengan orang lain yang berada di berbagai belahan dunia. Melalui media ini, mereka dapat memperoleh dan menyampaikan berbagai informasi yang dibutuhkan kapan saja dan dimana saja. Dengan jaringan yang global, internet dapat diakses setiap saat. Begitu memerlukan informasi tertentu, kita hanya perlu mengakses internet dan dengan cepat kita dapat memperoleh informasi apapun yang kita butuhkan.Informasi merupakan kebutuhan sehari-hari. Kebutuhan informasi menjadi masalah ketika kebutuhan tersebut tidak dapat terpenuhi.Internet memiliki berbagai layanan informasi, salah satunya disajikan melalui Website atau World Wide Web (WWW). Website adalah salah satu sumber daya internet yang paling cepat berkembang dan populer. Informasi web didistribusikan melalui pendekatan hypertext, yang memungkinkan suatu teks pendekatan menjadi acuan untuk membuka dokumen yang lain. Dengan adanya hypertext ini seseorang dapat memperoleh informasi dengan meloncat dari suatu dokumen ke dokumen yang lain (Kadir : 2003, 4). Semua informasi yang ada di Internet medianya adalah Website. Melihat begitu pesatnya perkembangan website sekarang ini, setiap penguna harus mampu memilih website mana yang berkualitas dan mampu memenuhi kebutuhan informasi mereka. Website pendidikan memberikan informasi yang dibutuhkan oleh mahasiswa Universitas. Informasi mengenai pendidikan merupakan informasi yang dibutuhkan oleh mahasiswa. Mahasiswa menghadapi kebutuhan informasi setiap hari dalam proses belajar mengajar. Selain sumber informasi yang berasal dari kampus, sekarang ini berkembang teknologi internet yang memberikan kemudahan dan keleluasaan dalam memberikan informasi seputar kampus. Website pendidikan di universitas berisi informasi-informasi seputar kampus. Sehingga mahasiswa kampus tersebut dapat mengetahui informasi hanya dengan mengakses website tersebut saja. Kualitas pelayanan dalam penyebaran informasi yang ada di website internet kampus telah menjadi kebutuhan yang sangat penting, karena hal tersebut berdampak terhadap tingkat kepuasan mahasiswa dan masyarakat luar. Pada akhirnya peningkatan kualitas pelayanan 
tersebut menjadi indikator keberhasilan kampus dalam meningkatkan Citra kampus di dunia internet. Website pendidikan yang akan diteliti adalah website FIK UBL. Di Universitas Bandar Lampung, Fakultas Ilmu Komputer merupakan satu-satunya fakultas yang memiliki website fakultas yang berbeda dari website kampus UBL. Untuk itu, membangun website membutuhkan informasi yang tepat dan dapat diandalkan. ISO (International Organisation for Standardisation) dan IEC (International Electrotechnical Commission) adalah lembaga standarisasi di dunia. ISO 9126 Software engineering - Product Quality adalah standar internasional untuk mengevaluasi kualitas perangkat lunak. Standar internasional ini terbagi menjadi 4 bagian yaitu model kualitas (ISO/IEC 9126-1), Metrik Eksternal (ISO/IEC 9126-2), Metrik Internal (ISO/IEC 9126-3), dan Metrik Kualitas Penggunaan (ISO/IEC 9126-4). Bagian yang akan diteliti untuk website FIK UBL yaitu, ISO/IEC 9126-4. ISO/IEC 9126-4 Metrik Kualitas Penggunaan adalah Standar Internasional yang diterbitkan oleh ISO dan IEC untuk pengukuran perangkat lunak mengenai kualitas penggunaan.Pada penelitian dengan judul "ANALISIS WEBSITE PENDIDIKAN BERBASIS ISO/IEC 9126-4 UNTUK PENGUKURAN KUALITAS PENGGUNAAN" (Lisa Devilia, 2012), kesesuaian level website FIK UBL telah diuji berdasarkan metriks-metriks didalam ISO/IEC 9126-4. Namun penelitian tersebut menghasilkan ketidaksesuaian level beberapa metriks dari ISO/IEC 9126-4. Oleh karena itu, dalam penelitian ini website kampus FIK UBL akan diimplementasikan berbasis ISO/IEC 9126-4 Metriks Kualitas Penggunaan. Sehingga Level-level kualitas dari website FIK UBL akan menghasilkan level yang sesuai dengan ISO/IEC 9126-4 Metrik Kualitas Penggunaan.

\section{a. Identifikasi Masalah}

Berdasarkan latar belakang di atas, identifikasi masalah yang muncul dalam Penelitian ini adalah:

a. Belum tercapainya kesesuaian level yang dibutuhkan didalam ISO/IEC 9126-4 Kualitas Penggunaan yang terdapat pada website Fakultas Ilmu Komputer Universitas Bandar Lampung, yaitu www.fik.ubl.ac.id.

b. Belum pernah dilakukan implementasi kualitas penggunaan website FIK UBL menurut ISO/IEC 9126-4 Kualitas Penggunaan.

\section{b. Batasan Masalah}

Untuk menghindari penyimpangan dari tujuan yang sebenarnya serta keterbatasan pengetahuan, maka Penelitian ini terfokus pada implementasi website www.fik.ubl.ac.id berbasis ISO/IEC 9126-4 Kualitas Penggunaan pada metriks efektivitas, produktivitas, dan kepuasan.

\section{c. Rumusan Masalah}

Rumusan Masalah yang ada didalam

Penelitian ini adalah:

a. Bagaimanakah implementasi www.fik.ubl.ac.id berbasis ISO/IEC 9126-4 Metrik Kualitas Penggunaan?

b. Apakah sudah tercapai kesesuaian level website pendidikan yang terdapat pada website Fakultas Ilmu Komputer, yaitu www.fik.ubl.ac.id setelah dilakukan implementasi terhadap ISO/IEC 9126-4 Metrik Kualitas Penggunaan?

\section{d. Tujuan dan Manfaat Penelitian}

\section{Tujuan Penelitian}

Penelitian ini bertujuan untuk:

a. Mengimplementasikan website FIK UBL www.fik.ubl.ac.id agar dapat memenuhi kebutuhan level dari ISO/IEC 9126-4 Metrik Kualitas Penggunaan.

b. Mengevaluasi implementasi website Fakultas Ilmu Komputer, yaitu www.fik.ubl.ac.idterhadap level kesesuaian dari ISO/IEC 9126-4 Metrik Kualitas Penggunaan.

\section{Manfaat Penelitian} Penelitian ini diharapkan:

a. Manfaat Praktis Penelitian ini diharapkan dapat digunakan sebagai tolak ukur tingkatan kualitas penggunaan website pendidikan berbasis ISO/IEC 9126-4.

b. Manfaat Teoritis dari Penelitian ini adalah diharapkan Penelitian ini dapat menghasilkan suatu metode pengukuran baru.

\section{e. Kerangka Pemikiran}

Berdasarkan uraian tersebut diatas, maka dapat disusun suatu kerangka pemikiran guna memperbaiki kesesuaian level pada penelitian "ANALISIS WEBSITE PENDIDIKAN BERBASIS ISO/IEC 9126-4 UNTUK PENGUKURAN KUALITAS PENGGUNAAN" (Lisa Devilia, 2012), agar dapat memenuhi levellevel metriks yang dibutuhkan dalam ISO/IEC 9126-4.Didalam ISO/IEC 9126-4 terdapat empat metriks, yaitu metriks efektivitas, produktivitas, keamanan, dan kepuasan. Namun dalam penelitian sebelumnya hanya satu metriks yang memiliki level yang sesuai dengan ISO/IEC 9126-4.

Adapun Kerangka pemikiran seperti gambar dibawah ini. 


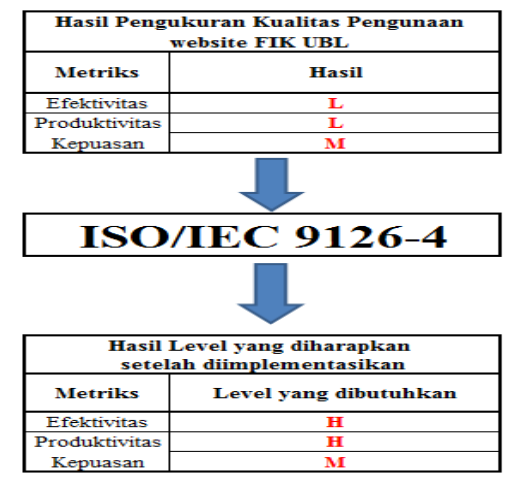

Gambar 1.1 Kerangka Pemikiran

\section{TINJAUAN PUSTAKA DAN LANDASAN TEORI}

\section{a. Tinjauan Pustaka}

Penelitian terdahulu yang telah dilakukan atau yang berkaitan dengan penelitian ini antara lain :

1. Penelitian Barnes dan Vidgen (2001), WebQual adalah instrumen untuk menilai kualitas website dari perspektif pengguna. WebQual yang menggabungkan tiga dimensi kualitas, antara lain kualitas informasi, kualitas interaksi, dan desain website yang berkualitas. Metode WebQual dibagi menjadi beberapa tahap, yaitu WebQual 1.0 yang menitikberatkan analisa kualitas informasi dan memiliki kekurangan di interaksi layanan, WebQual 2.0

2. Menurut Olsina dan Rossi (2002), Salah satu metode dapat digunakan untuk mengevaluasi kualitas website adalah Metode Evaluasi Kualitas Web (WebQEM). WebQEM adalah strategi evaluasi kuantitatif untuk menilai website dan kualitas aplikasi. Mendefinisikan dan mengukur indikator kualitas yang dapat membantu kepentingan stakeholder dan meningkatkan produk Web.

3. Menurut Sari, Dewi Kemala (2000), menyatakan bahwa web yang bermutu dapat dinilai dari 5 indikator yang meliputi aspek fungsi (functionality) yang sesuai dengan tujuan, desain (design) yang menarik, isi website (content) yang memenuhi kebutuhan pengunjung, originalitas web (originality) yang menunjukkan produk yang khas sebuah karya yang tidak duplikatif dari web lain, serta profesionalisme dan efektivitas (professionalism \& effectiveness). (Jha, 2009).

\section{b. Landasan Teori \\ 1. Defini Website}

Website atau World Wide Web adalah salah satu sumber daya internet yang paling cepat berkembang dan populer. Informasi web didistribusikan melalui pendekatan hypertext, yang memungkinkan suatu teks pendekatan menjadi acuan untuk membuka dokumen yang lain. Dengan adanya hypertext ini seseorang dapat memperoleh informasi dengan meloncat dari suatu dokumen ke dokumen yang lain (Kadir : 2003, 4). Pendapat tersebut di atas sejalan dengan apa yang dikemukakan oleh Rasiman (2005 : 9), bahwa dengan fasilitas www ini, host internet dapat dikunjungi dan menyajikan informasi dalam berbagai bentuk seperti teks, gambar, bunyi, musik animasi, dan video, yang penyajian informasinya menggunakan bahasa HTML (Hypertext Markup Language). Dan dapat diakses dengan menggunakan HTTP (hypertext transmission protocol atau hypertext transfer protocol).

\section{Unsur-Unsur Website}

AHP (Analytical Hierarkhi Process) pada dasarnya proses pengambilan keputusan adalah memilih suatu alternatif. Peralatan utama AHP adalah sebuah hierarki fungsional dengan input utamanya persepsi manusia.

\section{a) Domain}

Domain adalah nama unik yang diberikan untuk mengidentifikasi nama server komputer seperti web server atau email server di internet. Domain memberikan kemudahkan pengguna di internet untuk melakukan akses ke server dan mengingat server yang dikunjungi dibandingan harus mengenal deretan nomor atau yang dikenal IP. Domain terbagi menjadi tiga jenis level, yaitu Top level domain, Second Level Domain, dan Third Level Domain.

b) Hosting

Hosting adalah tempat anda menyimpan skrip atau media lainnya (gambar, mp3, video, dan sebagainya di internet (Agha A. Natasyah, 2010). Besarnya data yang dapat masuk, tergantung dari besarnya hosting yang disewa/dipunyai, semakin besar hosting semakin besar pula data yang dapat dimasukkan dan ditampilkan pada website. Besarnya hosting ditentukan ruangan harddisk dengan ukuran MB (Mega Byte) atau GB (Giga Byte). Hosting juga dapat diperoleh dengan menyewa. Lama penyewaan hosting rata-rata dihitung pertahun. Penyewaan hosting dilakukan melalui perusahaan-perusahaan penyewa web hosting yang banyak dijumpai di Indonesia maupun di luar negeri (Pardosi, 2001 : 288). 
c) Script/Bahasa Program

Script adalah bahasa yang digunakan untuk menerjemahkan setiap perintah dalam website pada saat diakses. Jenis script sangat menentukan statis, dinamis atau interaktifnya sebuah website. Semakin banyak ragam script yang digunakan maka akan terlihat website semakin dinamis, dan interaktif serta terlihat bagus. Kualitas website dapat terlihat dengan tanggapan pengunjung serta frekuensi kunjungan. Jenis jenis script yang banyak dipakai para designer antara lain HTML, ASP, PHP, JSP, Java Script, Java applet dan sebagainya. Bahasa dasar yang dipakai setiap website adalah HTML sedangkan ASP dan lainnya merupakan bahasa pendukung yang bertindak sebagai pengatur dinamis, dan interaktifnya website. Bahasa program ASP, PHP, JSP atau lainnya bisa dibuat sendiri. Script biasanya digunakan untuk membangun portal berita, artikel, forum diskusi, buku tamu, anggota organisasi, email, mailing list dan sebagainya yang memerlukan update setiap saat (Saputro : 2007).

d) Desain Web

Setelah melakukan penyewaan domain dan hosting serta penguasaan script, unsur website yang paling penting dan utama adalah desain.Desain web sangat menentukan kualitas dan keindahan website. Desain sangat berpengaruh kepada penilaian pengunjung akan bagus tidaknya sebuah website. Untuk membuat website dapat dilakukan sendiri atau menyewa jasa web designer. Kualitas website sangat ditentukan oleh kualitas designer. Jasa web designer pada umumnya memerlukan biaya yang tertinggi dari seluruh biaya pembangunan website. Namun itu semua tergantung pada kualitas web designer (Suyanto, 2007:3).

e) Program Transfer Data Kepusat

Setelah website selesai dibuat, maka perlu diletakkan di rumah hosting versi online agar dapat diakses oleh pengguna di seluruh dunia. Untuk itu pengguna akan diberikan akses FTP (File Transfer Protocol) setelah memesan sebuah web hosting untuk memindahkan file-file website ke pusat data web hosting. Untuk dapat menggunakan FTP diperlukan sebuah program FTP, misalnya WS FTP, Smart FTP, Cute FTP, dan lain lain. Program FTP ini banyak ditemui di internet dengan status penggunaan gratis maupun berbayar (Pardosi, 2001:289).

\section{f) Publikasi}

Keefektifan suatu website sangat tergantung dari besarnya jumlah pengunjung dan komentar yang masuk. Karena itu perlu mengenalkan website tersebut kepada masyarakat pengguna, yang dapat dilakukan melalui publikasi atau promosi. Publikasi website dapat dilakukan dengan cara seperti menyebarkan pamflet, selebaran, baliho dan sebagainya. Namun cara yang paling efektif dan efesien adalah publikasi langsung di internet melalui search engine (Yahoo, Google, Search Indonesia, dan sebagainya) karena tidak terbatas akan ruang dan waktu. Publikasi melalui search engine ada yang gratis dan membayar. Yang gratis biasanya terbatas dan cukup lama untuk dapat masuk dan dikenali oleh search engine terkenal. Cara publikasi yang efektif adalah dengan membayar, walaupun harus mengeluarkan dana akan tetapi website cepat masuk ke search engine dan dikenal oleh pengunjung (Saputro : 2007).

\section{METODE PENELITIAN}

\subsection{Analisa Kebutuhan}

Belum tercapainya level kualitas penggunaan pada penelitian sebelumnya, Oleh karena itu, pada penelitian ini akan dilakukan implementasi website FIK UBL terhadap ISO/IEC 9126-4. Perbaikan tersebut antara lain:

1. Pada metrik efektivitas, didalam website FIK UBL masih terdapat bagian-bagian dari website tersebut yang belum tepat, efektif, dan terdapat error yang terjadi, sehingga didalam penelitian ini akan mengimplementasikan bagian-bagian yang lebih tepat, efektif, dan tidak lagi terdapat error didalamnya.

2. Pada metrik produktivitas, didalam website FIK UBL masih belum produktif dari segi biaya, waktu, efisiensi, dan produktivitas ekonomi. Oleh karena itu, didalam penelitian ini akan mengimplementasikan website yang lebih produktif dari segi biaya, waktu, efisiensi, dan produktivitas ekonomi.

3. Pada penelitian tidak akan mengimplementasikan pada metriks keamanan, dikarenakan metriks keamanan bukan hanya diimplementasikan dari segi pembuatan website namun dari user dan pembuatannya.

4. Pada metrik kepuasan, didalam website FIK UBL sudah memuaskan para usernya, namun pada penelitian ini tetap akan memberikan kepuasan terhadap website kepada usernya.

Setelah dilakukan implementasi, didalam penelitian ini akan dilakukan evaluasi website FIK UBL kembali. Sehingga dapat diketahui hasil level implementasi kualitas penggunaan website FIK UBL berbasis ISO/IEC 9126-4 sudah sesuai atau belum dengan level yang dibutuhkan oleh ISO/IEC 9126-4. 


\subsection{Perancangan Penelitian}

Didalam penelitian ini, perancangan antarmuka website FIK UBL menggunakan CMS Joomla!. Joomla! Merupakan salah satu aplikasi web developer berbasis Content Management System yang banyak digunakan dalam membuat web sederhana dan kompleks, seperti web portal. CMS Joomla! yang digunakan merupakan versi terbaru, yaitu versi Joomla! 2.5. Template Joomla! yang digunakan adalah template endos. CMS Joomla! terdiri dari Back-End dan Front-End. Back-End adalah bagian website yang khusus diperuntukan bagi administrator untuk mengelola website-nya (management web). Sedangkan FrontEnd merupakan tampilan website sesungguhnya, karena tampilan jendela Front-End ini yang akan dilihat oleh publik (pengunjung). Berikut tampilan dari Backend Joomla!.

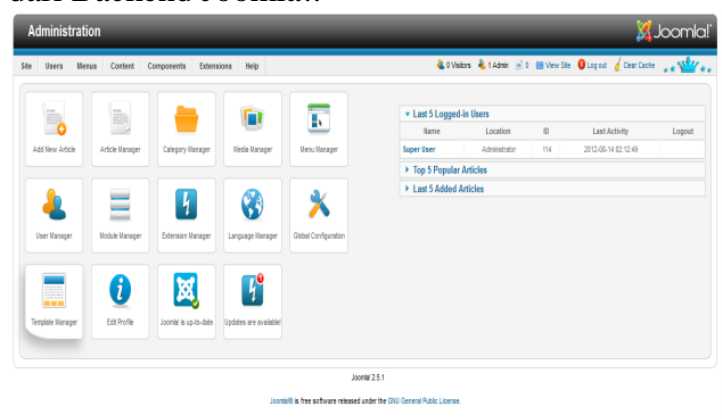

Gambar 3.1. Screen Shot Tampilan Back-End Joomla!

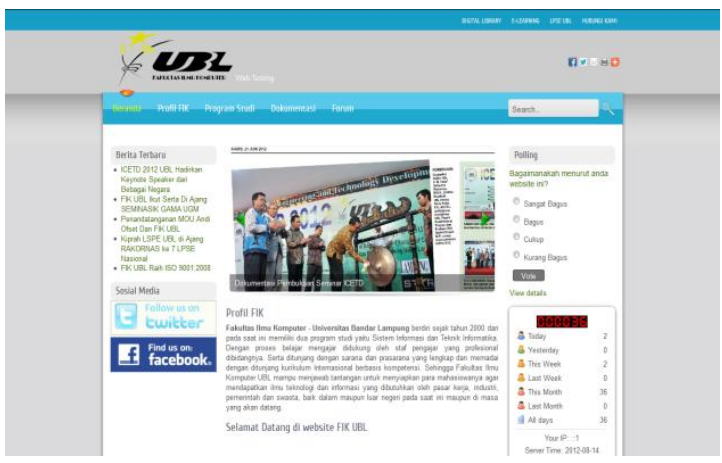

Gambar 3.2

Screen Shot Tampilan Front-End User

Pemodelan dengan $U M L$ mampu memberikan visualisasi, spesifikasi, konstruksi dan dokumentasi dari sebuah sistem perangkat lunak.UML merupakan sebuah "bahasa" yang telah menjadi standar dalam industri untuk visualisasi, merancang dan mendokumentasikan sistem piranti lunak.Dengan menggunakan $U M L$ dapat dibuat model untuk semua jenis aplikasi piranti lunak, dimana aplikasi tersebut dapat berjalan pada piranti keras, sistem operasi dan jaringan apapun, serta ditulis dalam bahasa pemrograman apapun.Model $U M L$ terdiri atas banyak elemenelemen grafis yang digabungkan membentuk diagram.Tujuan representasi elemen elemen grafis ke dalam diagram adalah untuk menyajikan beragam sudut pandang dari sebuah sistem berdasarkan fungsi masing-masing diagram tersebut.Kumpulan dari beragam sudut pandang inilah yang disebut sebuah model.UML yang dipakai di penelitian inisebagai berikut:

a) Use Case Diagram

b) Activity Diagram

Use Case adalah perilaku atau apa yang dikerjakan oleh pengguna sistem aplikasi, termasuk interaksi antara Aktor dengan software aplikasi tersebut. Dengan diagram use case ini dapat diketahui proses yang terjadi pada aplikasi.

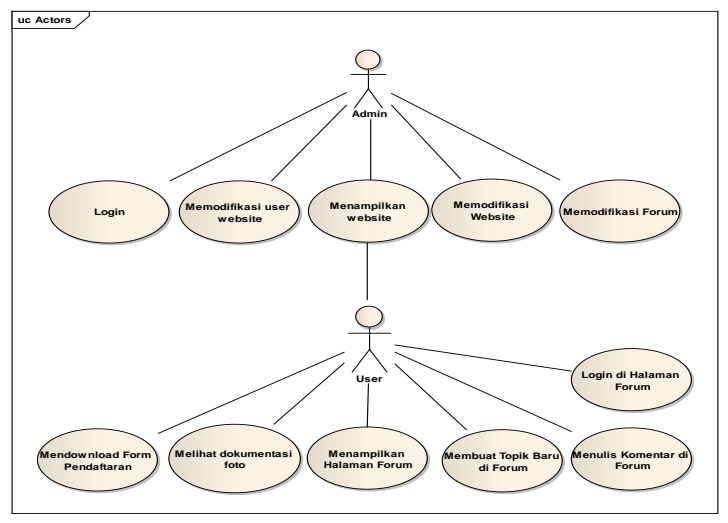

Gambar 3.3 Use Case Diagram website

Activity diagram adalah salah satu cara untuk memodelkan event- event yang terjadi dalam suatu use case. Secara esensial, activity diagram mirip dengan diagram alir (flowchart) karena memperlihatkan aliran kendali dari suatu aktifitas ke aktifitas lainnya (Nugroho, 2005:61). Berikut adalah activity diagram secara keseluruhan proses yang terjadi di dalam implementasi website FIK UBL berbasis ISO/IEC 9126-4.

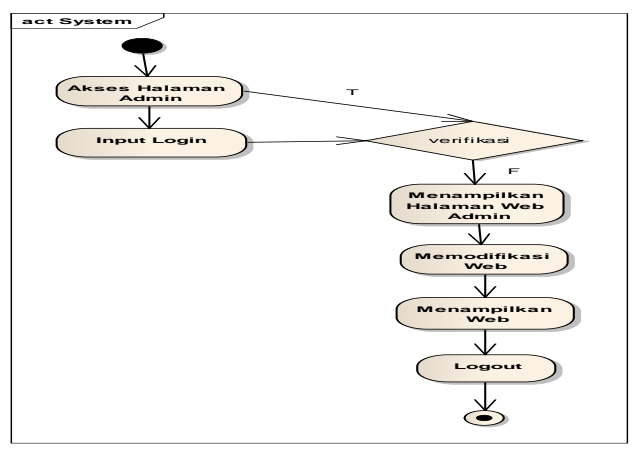

Gambar 3.4 Activity Diagram Admin 


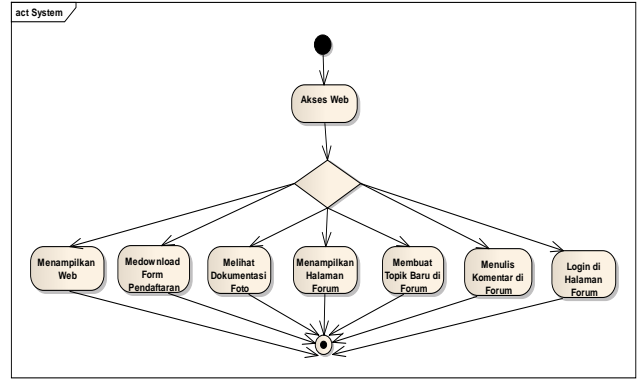

Gambar 3.5

Activity Diagram User

\subsection{Variabel Penelitian}

Variabel Penelitian yang dipakai dalam Penelitian ini terdapat didalam ISO 9126-4 tentang pengukuran kualitas penggunaan yaitu:

\section{Metrik Efektivitas}

Metrik Efektivitas menilai apakah tugas-tugas yang dilakukan oleh pengguna mencapai tujuan tertentu dengan akurasi dan kelengkapan dalam konteks tertentu digunakan.

\section{Metrik Produktivitas}

Metrik produktivitas menilai sumber daya yang pengguna konsumsi dalam kaitannya dengan efektivitas yang dicapai dalam konteks tertentu yang digunakan. Sumber daya yang paling umum adalah waktu untuk menyelesaikan tugas, meskipun sumber daya yang relevan lainnya dapat mencakup usaha pengguna, bahan atau biaya penggunaan keuangan.

\section{Metrik Kepuasan}

Metrik kepuasan menilai sikap pengguna terhadap penggunaan produk dalam konteks penggunaan tertentu.Kepuasan dipengaruhi oleh persepsi pengguna tentang sifat-sifat produk perangkat lunak (seperti yang diukur dengan metrik eksternal) tentang efisiensi, produktivitas, dan keselamatan dalam penggunaan.Metrik Kepuasan dibagi menjadi berikut:

a. Skala Kepuasan

Di subvariabel ini mengunakan metode elemen data perhitungan yaitu:

$$
\mathrm{X}=\mathrm{A} / \mathrm{B}
$$

Keterangan:

$\mathrm{A}=$ kuesioner memproduksi skala psikometrik

$\mathrm{B}=$ rata-rata populasi

b. Kuesioner Kepuasan

Di subvariabel ini mengunakan metode elemen data perhitungan yaitu:

$$
\mathrm{X}=\Sigma\left(\mathrm{A}_{\mathrm{i}}\right) / \mathrm{n}
$$

Keterangan:

$\mathrm{A}_{\mathrm{i}}=$ tanggapan terhadap pertanyaan

$\mathrm{n}=$ jumlah tanggapan

c. Kebijaksanaan Dalam Penggunaan

Di subvariabel ini mengunakan metode elemen data perhitungan yaitu:

$$
\mathrm{X}=\mathrm{A} / \mathrm{B}
$$

Keterangan:

$\mathrm{A}=$ jumlah penggunaan perangkat lunak digunakan

$\mathrm{B}=$ jumlah pengguna diharapkan menggunakan perangkat lunak.

\section{HASIL DAN PEMBAHASAN}

\section{a. Website FIK UBL}

Website FIK UBL merupakan website pendidikan dari Fakultas Ilmu Komputer di Universitas Bandar Lampung. Nama domain dari website FIK UBL adalah www.fik.ubl.ac.id. Website FIK UBL merupakan subdomain dari website www.ubl.ac.id. Website tersebut mengunakan ac.id sebagai Country Code Top level domain, domain utamanya adalah UBL, dan Third level domainnya adalah FIK. Website FIK UBL mempunyai Hosting Server di provider Nusanet. Dari segi design website FIK UBL juga memakai CMS, yaitu CMS Joomla!. Dalam proses membangun sistem website ini dibutuhkan beberapa software seperti, Xampp 1.7.7, CMS Joomla! 2.5, serta Mozilla Firefox. Implementasi website FIK UBL terhadap ISO/IEC 9126-4 pada www.fik.ubl.ac.id/fik.

\section{b. Struktur Menu Website}

Desain menu dalam perancangan website FIK UBL berbasis ISO 9126-4 untuk Front-End website User sebagai berikut.

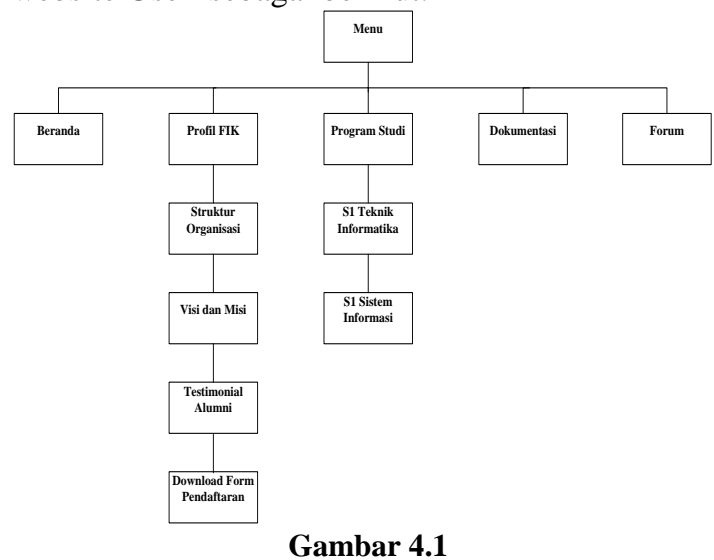

Struktur Menu Front-End website

\section{c. Hasil Kuesioner}

Setelah dilakukan penyebaran kuesioner, diperoleh hasil respons dari user website FIK UBL. Kuesioner ini terdiri dari 7 pertanyaan yang memuat metriks efektivitas, produktivitas, dan kepuasan. Didalam Kuesioner terdapat skala 1-9, yang setelah dianalisa skala tersebut diterjemahkan menjadi 3 jenis Level yaitu Low, Medium, dan High. Low (L) merupakan skala 1-3, Medium (M) merupakan skala 4-6, dan High (H) merupakan skala 7-9 yang terdapat didalam kuesioner. Hasil data kuesioner dapat disimpulkan didalam grafik untuk setiap pertanyaannya seperti dibawah ini: 


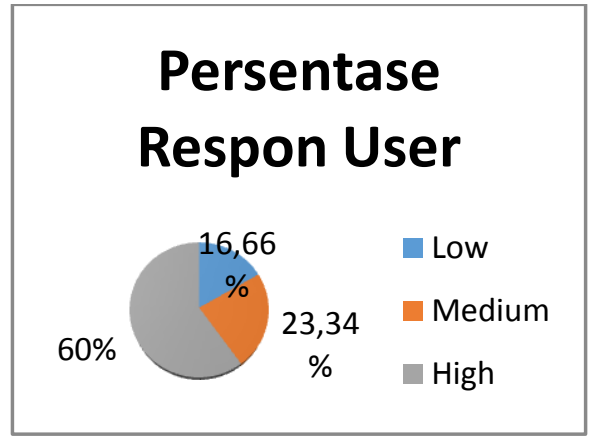

Gambar 4.2 Grafik Persentase Respon User Kuesioner Pertanyaan 1

\section{Persentase Respon User}

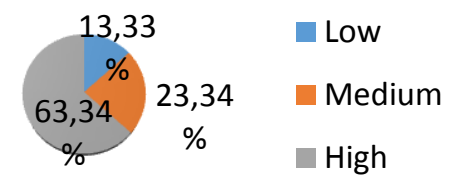

Gambar 4.3 Grafik Persentase Respon User Kuesioner Pertanyaan 2

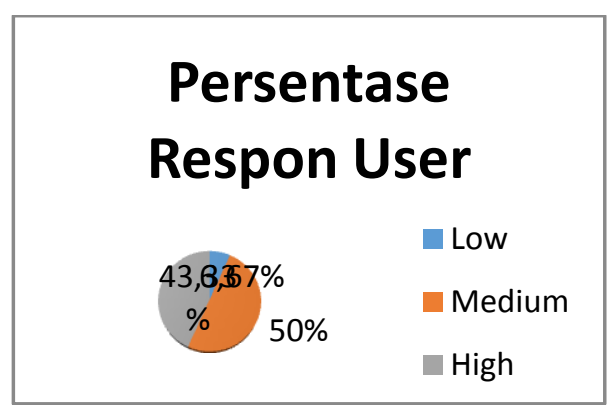

Gambar 4.4 Grafik Persentase Respon User Kuesioner Pertanyaan 3

Tabel 4.1 Hasil Level Kuesioner

\begin{tabular}{|c|c|}
\hline Metriks & Level \\
\hline Efektivitas & $\mathrm{H}$ \\
\hline Produktivitas & $\mathrm{H}$ \\
\hline Kepuasan & $\mathrm{M}$ \\
\hline
\end{tabular}

\section{KESIMPULAN DAN SARAN}

\section{a. Kesimpulan}

Setelah mengimplementasi website FIK

UBL berdasarkan ISO/IEC 9126-4 dan menganalisa hasil kuesioner, hasil kuesioner tersebut dibandingkan dengan level yang dibutuhkan didalam standar ISO/IEC 9126-4. Berdasarkan Penelitian secara keseluruhan menghasilkan beberapa temuan penting yang dapat dirumuskan dalam kesimpulan sebagai berikut:
1. Metriks Efektivitas didalam penelitian ini menghasilkan level High, sedangkan Level yang dibutuhkan adalah High. Sehingga Hasil Penelitian menyatakan Metriks Efektivitas pada website FIK UBL sesuai dengan standar ISO/IEC 9126-4.

2. Metriks Produktivitas didalam penelitian ini menghasilkan level High, sedangkan Level yang dibutuhkan adalah High. Sehingga Hasil Penelitian menyatakan Metriks Produktivitas pada website FIK UBL sesuai dengan standar ISO/IEC 9126-4.

3. Metriks Kepuasan didalam penelitian menghasilkan level Medium, sedangkan Level yang dibutuhkan adalah Medium. Sehingga Hasil Penelitian menyatakan website FIK UBL di Metriks Kepuasan sesuai dengan standar ISO/IEC 9126-4.

4. Dari 3 Metriks Standar ISO/IEC 9126-4 yang diteliti, Semua Metriks yang diimplementasikan terhadap website FIK UBL sudah sesuai dengan Standar ISO/IEC 9126-4.

b. Saran

Adapun saran-saran yang dapat disampaikan oleh penulis adalah:

1. Bagi Penelitian terhadap website FIK UBL mendatang seharusnya dapat diperluas lagi ke metriks lainnya pada ISO/IEC 9126.

2. Untuk komponen dari website FIK UBL masih bisa ditambah agar kualitas penggunaan dari website tersebut menjadi lebih baik.

\section{DAFTAR PUSTAKA}

1. 9126-4: Software Engineering - Software Product Quality - Part 4: Quality In Use Metrics. 2002. Canada: ISO/IEC

2. 9126-3: Software Engineering - Software Product Quality - Part 3: Internal metrics. 2002. Canada: ISO/IEC.

3. 9126-2: Software Engineering - Software Product Quality - Part 2: External Metrics. 2001. Canada: ISO/IEC.

4. 9126-1: Software Engineering - Software Product quality - Part 1: Quality Model. 2000. Canada: ISO/IEC.

5. Simarmata, Janner. 2007. Rekayasa Perangkat lunak. Yogyakarta: Penerbit Andi.

6. Barnes, Stuart \& Vidgen, Richard. WebQual: An Exploration of Web-site Quality.United Kingdom: School of Management, University of Bath.

7. Olsina, Luis \& Rossi, Gustavo.2002. Measuring Web Application Quality with WebQEM. Argentina: La Pampa National University \& La Plata National University 
8. Barnes, Stuart \& Vidgen, Richard. 2000. Assessing The Quality of Auction Web Sites. United Kingdom: School of Management, University of Bath.

9. Bevan, Nigel. 2000. Quality In Use For All.

10. Sari, Dewi Kemala. 2000. Evaluasi Pemanfaatan Situs Chem-is-try.org dalam Pemenuhan Kebutuhan Informasi oleh Mahasiswa Departemen Kimia Fakultas Matematika dan Ilmu Pengetahuan Alam (FMIPA) USU. Medan: Universitas Sumatra Utara. 